East African Medical Journal Vol. 77 May No. 52000

QUALITY OF CARE AND ITS EFFECTS ON UTILISATION OF MATERNITY SERVICES AT HEALTH CENTRE LEVEL.

G.S. Lule, MBChB, MPH, PhD, FRIPHH, Associate Professor and Head, Department of Community Health, College of Medicine, University of Malawi,

J. Tugumisirize, MBChB, MSc, MMed, Lecturer and Head, Department of Psychiatry, College of Medicine, University of Malawi. M. Ndekha, BSc, MSc,

Lecturer, Department of Community Health, College of Medicine, University of Malawi, Private Bag 360, Chichiri, Blantyre 3, Malawi.

Request for reprints to: Professor G.S. Lule, Private Bag 360, Chichiri, Blantyre 3, Malawi.

\title{
QUALITY OF CARE AND ITS EFFECTS ON UTILISATION OF MATERNITY SERVICES AT HEALTH CENTRE LEVEL
}

\section{G.S. LULE，J. TUGUMISIRIZE and M. NDEKHA}

\begin{abstract}
Objective: To determine antenatal attendance and place of delivery of women in Chilomoni health centre catchment area and how they perceived the quality of health care provided at the health centre.

Design: A cross-sectional household survey.

Subjects: Women aged between fifteen and forty nine years, who had delivered at least one child, and had stayed in Chilomoni health centre catchment area during the past five years. Results: Of the 1108 women interviewed, $52 \%$ reported for antenatal care at the health centre, but only eight per cent used it for delivery. Reasons for not using the health centre were mainly family refusal and poor facilities at the health centre $(68 \%)$. On the quality of care, $97 \%$ were satisfied with the providers' attitudes, $91 \%$ with communication, $86 \%$ with the providers technical competence in general, $97 \%$ with working hours, but only $37 \%$ were satisfied with privacy. Only four per cent were satisfied with the supply of drugs. Variables independently associated with non use of the health centre were: lack of drugs (OR 2.8, $p=$ $001)$, poor ambulance service (OR 2.4, $p=0.03)$, poor laboratory services $(O R 1.7, p=001)$, long waiting time (OR 1.6, $p=0.02)$ and lack of privacy $(\mathrm{OR} 1.5, \mathrm{p}=\mathbf{0 . 0 1})$.

Conclusion: Few women use Chilomoni health centre for antenatal services and still fewer use it for delivery. Reasons for not using the health centre included refusal by the family members and the poor facilities at the health centre. We recommend that the facilities at Chilomoni health centre be improved immediately.
\end{abstract}

\section{INTRODUCTION}

One of the greatest risks to the health of a Malawian woman is childbearing $(1,2)$. This is evidenced partly by the very high mortality rate of 620 per 100,000 live births(3). Worldwide maternal health services directed towards the improving women's health are now receiving the attention they deserve with the focus and emphasis put on the concept of "Reproduction Health" which is a partnership approach in the provision of quality care to the whole woman and taking into consideration the well being of the entire family (4). This quality care must be provided with compassion, dignity, confidentiality, continuity and informed choice(5). This approach has led to quality assessment in reproductive health services which examines service delivery in a comprehensive manner, taking into account the points of view of health facility users, quality of services at a structural level and describes how quality services are actually delivered (process) and how these relate to health facilities use(6).

Queen Elizabeth Central Hospital (QECH), situated in the centre of the city of Blantyre is a teaching hospital, a National referral Hospital, a District Hospital and a local health facility for the residents of the city and its surroundings. Five peri-urban health units were built to increase access to health care, especially to the pregnant women living in the peri-urban areas of Blantyre city thereby easing the work overload at QECH. Despite that, QECH continues to be overcrowded by mothers from the peri-urban areas. This puts undue pressure on the limited resources available, and thereby reduces the quality of care. Chilomoni health centre, situated 13 kilometres from $\mathrm{QECH}$, is one of the five peri-urban health units. Its maternity wing offers antenatal care and delivery services to low risk mothers.

This study set out to investigate, with special reference to quality of care, why so many women continue to go to QECH and not use these peri-urban health centres. It is hoped to use this information to make recommendations on how to increase coverage in the utilisation of maternity services of the peri-urban health units, especially Chilomoni maternity unit, by pregnant women, and also to draw the attention of those concerned to take the appropriate action.

\section{MATERIALS AND METHODS}

A cross-sectional household survey was undertaken in the catchment area of Chilomoni health centre. The study population included all women aged between 15-49 years of age, who had 
delivered at least one child, and had stayed within Chilomoni health centre catchment area during the last five years.

Based on the estimated 50\% use of Chilomoni health centre, and a desired precision of three per cent, at $95 \%$ Confidence Interval, a minimum sample size of 1067 was calculated using the formula of single proportions(7). The sixteen villages where the study was carried out were selected through a multi-stage method(8). First, each village in the catchment area was put in a cluster based on distances of 5, 10, 15 and more than 15 kilometres from the health centre. Four villages were then randomly selected from each cluster.

For the measurement of quality of care as perceived by the respondents, a conceptual framework adapted and modified from Bruce's(9) framework for the assessment of quality of care was used. This constituted the following main elements: the woman-provider relationship including privacy and provider sincerity. The technical competence of the providers including information exchange and understanding, comprehensiveness of the examination. Women's rating of facility itself in terms of the buildings, and cleanliness and how these affect their attendance to the health centre. The availability of laboratory services, and drugs including antibiotics, analgesics, iron supplements. antimalarials, and other supplies like bedding, cotton wool, and gloves. Management issues including working hours, waiting time, scheduling of appointments, and availability of ambulance services if a woman was referred during labour.

In addition, information was collected from each woman which included age, marital status, education background, number of children, places where antenatal care was attended and where delivery took place. Also included in the information collected was an inquiry into the reasons for use or non use of the maternity services offered at Chilomoni health centre.

The information from the women was collected using a multi-structured and open-ended questionnaire which had been developed after a pilot study in the same geographical area. In order to avoid biased answers, the interview questions were phrased in both positive and negative directions. Due to the high illiteracy rate among these women, the questionnaire was administered in the local language to individual mothers in their homes by the researchers.

All the participants were clearly informed that the purpose of the survey was to examine their antenatal histories, places of delivery, and how they judged the quality of care they received and its impact on their use of Chilomoni health centre.

The structure and process of maternity care delivery at the health centre were also observed by the principal investigator (GSL) who visited the health centre during the study period and attended ten antenatal clinics from start to finish. He did not observe any deliveries because they were few, far between and therefore difficult to have enough numbers on which to base meaningful conclusions. The observer used a checklist to obtain information on several indicators related to elements of quality maternity care at the levels of both structure and process. This was important in order to validate the results of the women's reports on the quality of care provided with the observation results.

All data were analysed using Epi-Info version 6.0 and SPSS software. Descriptive statistics were determined on the respondents' socio-demographic characteristics. Following calculation of Chi-square tests on univariate correlates on maternity services use, a multivalent analysis was conducted on those variables which had a high statistical significant of association with use or non use of the maternity services at the health centre. A logistic-regression model was used to determine the independent contribution of these variables to use or non use of the health centre maternity services.

\section{RESULTS}

Interview: All the 1108 women approached accepted to be interviewed and all responded to the questionnaire, although some were undecided about a few of the indicators. The respondents had a mean age of 17.8 years (SD 6.3). Eighty five per cent of the respondents were married or living with a regular partner. Nearly $80 \%$ of these women had never been to school and therefore illiterate. Nineteen per cent were primiparas $4: 1 \%$ of the multiparous women had had five or more deliveries. Fifty two per cent of the multiparous respondents attended antenatal clinics at Chilomoni health centre during the previous pregnancy. However, only eight per cent of them ended up delivering at the health centre. One hundred and sixty eight women were pregnant at the time of the survey and $65(38.7 \%)$ of them were attending antenatal at Chilomoni health centre.

The reasons given by the respondents for attending antenatal clinics at Chilomoni health centre during the present and/or previous pregnancies are shown in Table 1. For both present and previous pregnancies, about $90 \%$ of the respondents reported that they had attended the antenatal clinic to either get an obstetric check, for tetanus toxoid shot, or to ensure that they would not be sent away during labour. Nearly one fourth of the 65 women who were using antenatal services at the health centre at the time of the survey, did so because of ill health.

\section{Table 1}

Reasons given for attending antenatal clinics at Chilomoni Health Centre

\begin{tabular}{|c|c|c|c|c|}
\hline Reason & $\begin{array}{l}\text { Present } \\
\text { pregnancy } \\
(\%) \\
(\mathrm{n}=65)\end{array}$ & $\begin{array}{l}\text { Previous } \\
\text { pregnancy } \\
(\mathrm{n}=467)\end{array}$ & $\chi^{2}$ & $\mathrm{p}$ value \\
\hline For obstetric check & 91 & 92 & 0.13 & NS \\
\hline For tetanus toxoid & 87 & 88 & 0.01 & NS \\
\hline \multicolumn{5}{|l|}{ To avoid being sent } \\
\hline away when in labour & 90 & 94 & 0.99 & NS \\
\hline \multicolumn{5}{|l|}{ Relatives requested } \\
\hline attendance & 55 & 39 & 4.63 & 005 \\
\hline \multicolumn{5}{|l|}{ For haematenics and } \\
\hline antimalarials & 31 & 24 & 1.41 & NS \\
\hline Was not feeling well & 24 & 29 & 0.52 & NS \\
\hline For health education & 20 & 25 & 0.79 & NS \\
\hline To accompany friends & 1 & 0 & 7.19 & 0.01 \\
\hline
\end{tabular}

$\mathrm{NS}=$ difference not statistically significant

Regarding the actual place of delivery during the previous pregnancy. Table 2 shows the total number of women who used the various health facilities available during antenatal period and delivery The sum total in the antenatal column was more than 1108 because some of the women went to the Chilomoni health centre at one time and also went to other health facilities. For instance, women considered to be high risk went to the Chilomoni health centre and were later referred to the QECH Hospital, thereby visiting two institutions. 
Table 2

Utilisation of antenatal and delivery services in the health facilities available

\begin{tabular}{lrrrr}
\hline Health care & \multicolumn{2}{c}{ Antenatal } & \multicolumn{2}{c}{ Delivery } \\
\cline { 2 - 5 } & No. & $(\%)$ & No. & $(\%)$ \\
\hline Chilomoni H/C & 770 & $(51.9)$ & 89 & $(8.0)$ \\
QECH & 438 & $(29.5)$ & 296 & $(26.7$ \\
Misidi Mission H/C & 91 & $(6.1)$ & 135 & $(12.3)$ \\
Home care (no ANC) & 89 & $(6.0)$ & 453 & $(40.9)$ \\
Private Hospital & 82 & $(5.5)$ & 47 & $(4.2)$ \\
TBA & 14 & $(1.0)$ & 88 & $(7.9)$ \\
\hline Total & $1484 *$ & & 1108 & $(100.0)$ \\
\hline
\end{tabular}

* The sum total in the antenatal column is more than 1108 because some women went to the Chilomoni Health Centre at one time and also went to another health facility.

- TBA $=$ Trained Traditional Birth Attendant

Although the Chilomoni maternity unit was the most patronised facility by pregnant women during their antenatal period, it was the least patronised of all health institutions during delivery. Of the 541 (48.8\%) who delivered outside the health institutions, $83.7 \%$ were not attended to or were attended to by non-trained personnel during child birth; the other $16.3 \%$ were attended to by trained traditional birth attendants (TBAs). Those who were not attended to or were attended by non-trained personnel during child birth, included 28 primigravidae and 17 women who had delivered 10 or more children.

Relatively fewer women used the private health facilities for maternity care and delivery. This was a result of the fees that they charge.

Respondents who said they did not use the matemity services were asked to give their reasons and responses are shown in Table 3. A surprisingly large percentage (68.2\%) indicated that relatives had refused them to go to the health centre for antenatal or when in labour. This shows how some members of the family can infiuence the decision to

Table 3

Reasons for not using the health centre (percentages)

\begin{tabular}{lrrrrr}
\hline & $\begin{array}{r}\text { Antenatal } \\
(\mathrm{n}=533)\end{array}$ & $\begin{array}{r}\text { Delivery } \\
(\mathrm{n}=1019)\end{array}$ & Both & $\chi 2$ & $\mathrm{p}$ value \\
\hline Reason & & & & & \\
Poor facilities & 56.5 & 78.5 & 67.8 & $82.4]$ & 0.001 \\
Family refusal & 66.2 & 70.2 & 68.2 & 2.53 & $\mathrm{NS}$ \\
Distance & 34.4 & 47.1 & 40.8 & 23.44 & 0.001 \\
Labour at night & 0.0 & 16.7 & 10.3 & 100.00 & 0.001 \\
Poor staff attitude & 1.0 & 1.4 & 1.2 & 0.54 & $\mathrm{NS}$ \\
\hline
\end{tabular}

- The percentages add up to more than 100 because some respondents gave more than one reason.

NS $=$ difference not statistically significant.

seek health care. This decision is usually taken by the mother-in-law. Poor facilities at the health centre was another main reason for not using both antenatal and delivery services. Only $1.2 \%$ ofthe respondents mentioned attitude of staffas a barrier to maternity services use.
Although the majority (96\%) of the mothers walked to the health centre, only $40 \%$ mentioned that distance was the reason for not using Chilonnoni health centre. A carefull look at the number of women who gave distance as a reason for non-use of Chilomoni Health Centre by age-group, parity, job, marital status and distance from the health centre suggests that they were over 40 years, between parity 7-10, had no job for income, were married and stayed far from the health centre.

Health care at Chilomoni health centre is free and this is why no one mentioned cost as a hindrance for utilising the maternity services, but other opportunity costs like working on the farm, fetching water and firewood and other reasons will be worth considering.

Results of the respondents' reports on the quality of care indicators as reported by those $679(61.3 \%)$ women who had used Chilomoni health centre, for maternity care, at any one time during the past five years, are shown in Table 4. The results demonstrate major variations in the responses reported based on the elements and the indicators studied. A much higher percentage of women were satisfied

Table 4

Responses to conceptual framework elements for quality in maternity care by general satisfaction

\begin{tabular}{|c|c|c|c|}
\hline \multirow{3}{*}{ Component } & \multicolumn{3}{|c|}{ Satisfied } \\
\hline & & & No \\
\hline & $\mathrm{N}$ & $\%$ & $\mathrm{~N}$ \\
\hline
\end{tabular}

Woman-provider relationship

General attitude

Communication

Sincerity

Privacy

Provider's technical competence

Understanding of subjects discussed

Comprehensiveness of physical examination

Measured height

Measured weight

Measured BP

Examined eyes (anaemia)

Examined for leg oedema

Infrastructure

Quality of building

Cleanliness

Space

Smell

Facilities/provisions

Antimalarials

Iron supplements

Other drugs

Cotton wool

Gloves

Laboratory services

$\begin{array}{lrrr}660 & 97.2 & 19 & 2.8 \\ 616 & 90.7 & 63 & 9.3 \\ 474 & 69.8 & 205 & 30.2 \\ 363 & \text { S3.5 } & 316 & 46.5\end{array}$

Management

Working hours

Waiting time

Scheduling of appointments

Ambulance services
86.2

70.3

23.0

96.6

82.1

55.7

$82.5 \quad 119$

560

619

331

556

326

359

81

28

3

206

17

661

113

536

7 $\begin{array}{lll}91.1 & 60 & 8.9\end{array}$

$48.7 \quad 348 \quad 51.3$

$82.0 \quad 123 \quad 18.0$

$48.0 \quad 353 \quad 52.0$

$\begin{array}{lll}52.8 & 320 & 47.2\end{array}$

$11.9 \quad 598 \quad 88.1$

$\begin{array}{lll}4.1 & 651 & 95.9\end{array}$

$\begin{array}{lll}0.5 & 676 \quad 99.5\end{array}$

$\begin{array}{lll}30.3 & 473 & 69.7\end{array}$

$2.9 \quad 662 \quad 97.1$

$\begin{array}{lll}97.4 & 18 & 2.6\end{array}$

$\begin{array}{lll}16.7 & 566 & 83.3\end{array}$

$\begin{array}{lll}79.0 & 143 & 21.0\end{array}$

$1.1 \quad 672-98.9$


with the providers general attitudes, and the communication process that took place between themselves and the health care providers. On the other hand, many of them doubted the providers' sincerity, especially as regards to the facilities offered at the health centre. The study demonstrated that $47 \%$ of the women reported dissatisfaction with the lack of a private atmosphere for service delivery, and they indicated that this lack of privacy, greatly affected their attendance of the maternity services.

The results show a varied satisfaction of women on indicators of providers technical competence on pregnancyrelated issues. The majority of them were satisfied with the providers understanding of the subjects discussed, and the way the providers carried out the general physical examination. However of concern was the finding that many of the health providers did not measure the women's height. The data also demonstrate which indicators of infrastructure and facilities are major contributors to women dissatisfaction.

For instance while over $90 \%$ of the respondents were satisfied with the quality and available space in the maternity building, nearly $50 \%$ of them indicated that they were not satisfied with cleanliness and smell of the place.

The highest rate of dissatisfaction was given to the poor facilities with an overwhelming majority of the respondents indicating that the facilities offered at the health centre were poor. For example, simple laboratory tests like haemoglobin and urinalysis were not done. The lack of satisfaction with facility indicators was associated with lack of use of the health centre with many women mentioning that they did not use the health centre because of the poor facilities.

With regards to administrative management, although the majority of women reported the working hours as convenient and the scheduling of appointments as satisfactory, many women were dissatisfied with the waiting time which they thought was too long. Almost all the respondents expressed dissatisfaction with the ambulance services. This was mainly because the health centre did not have an ambulance of its own but relied on one being sent from QECH whenever required. However, this arrangement proved to be extremely unsatisfactory even to the health staff themselves.

A logistic regression model was established using dissatisfaction responses which showed a significant association with non use of Chilomoni health centre by the mother. Table 5 shows that five of the responses that emerged as being independently associated with the mother not using Chilomoni health centre for maternity services. The strongest association was the constant lack of other drugs, for example, antibiotics and analgesics at the health centre. When facilities/provisions were grouped together, women who were dissatisfied with the facilities offered at the health centre were 13 times more likely not to use the health centre than those who were satisfied with the facilities.
Table 5

Variables associated with non use of chilomoni health centre for maternity services.

\begin{tabular}{lccrr}
\hline Variable & $\begin{array}{c}\text { Odds } \\
\text { Ratio }\end{array}$ & $95 \%$ CI & $\chi 2$ & p Value \\
\hline $\begin{array}{l}\text { Lack of drugs } \\
\begin{array}{l}\text { Poor ambulance } \\
\text { services }\end{array}\end{array}$ & 2.8 & $16-4.7$ & 17.5 & 0.001 \\
$\begin{array}{l}\text { Poor laboratory } \\
\text { services }\end{array}$ & 2.4 & $1.0-5.8$ & 4.6 & 0.030 \\
$\begin{array}{l}\text { Long waiting time } \\
\text { Lack of privacy }\end{array}$ & 1.7 & $1.2-2.5$ & 20.4 & 0.001 \\
\hline
\end{tabular}

$\mathrm{CI}=$ Confidence Interval

Health centre observations: At the time of the study, Chilomoni health centre was undergoing renovations to improve on its buildings most of which were in a state of disrepair. The building in which the maternity, antenatal and delivery services are carried out was spacious, wellventilated and illuminated. It consisted of a maternity ward in which postnatal mothers were admitted, and the delivery room. In addition, it had a bathroom, but it did not have a waiting room. The delivery room which also served as the examination room for antenatal mothers was equipped with an examination couch, a stethoscope, a foetoscope, a sphygmomanometer, a weighing scale and only one screen. However lacking were a sheet to cover women, and height scales.

Although a mini-laboratory was available, meant to undertake analysis, haemoglobin and VDRL investigations, it was non functional due to lack: of reagents, and the fact that there was no laboratory technician available. As a result of this, those women who were thought to be in special need of these investigations were either referred to QECH or had their blood and urine samples sent to be processed at QECH. A dispensary (pharmacy) was available in one setting for the whole health centre, but it suffered from a serious shortage of almost all kinds of medicines. The staff responsible for the provision of maternity care consisted of two nurse midwives and a nurse aid.

There were established days for antenatal care: one day allotted to newly registered mothers, and one day for subsequent cases. Due to shortage of staff, women were discouraged to visit on any day. Women were seen between 8.30 a.m. and noon, which prevented some women, who had a medical complaint, from seeing the medical assistant.

Once again due to the shortage of staff, the women spent a lot of time at the health centre waiting to be examined. The mean time spent at the health centre was 90 minutes. Waiting to see the Medical Assistant lasted for a shorter period of time, since the Medical Assistant only saw cases with "complicated" medical problems referred by the midwives. On the whole, women spent a mean time of 7.7 hours (SD 4.3) travelling from home to the health centre, receive the service and back home. 
On arrival at the health facility, the women had to wait for the health providers. Since there was no waiting room, the women crowded in a narrow corridor. However, women were generally welcome and treated in a kind and respectful way. All women were registered during each visit. The newly registering women were seen by the midwife and the nurse aid. Their socio-demographic, obstetric, and family histories were recorded on an antenatal card. The questions on the antenatal card were asked as a routine. Even when a woman volunteered to give more information, she was not given enough time to explain.

Weight and the blood pressure measurements were hurriedly taken by the midwives. The physical examination, was concentrated mainly on abdominal palpation to estimate the number of weeks of gestation. The foetal heart beat was listened to. A quick glance at the conjunctiva, and a check on leg oedema would be performed among most of the women. However, other important and relevant areas such as the lips and gums, the thyroid gland, the breasts and nipples, and any varicose veins in the legs were not examined. Vaginal examination was not conducted on any woman and no laboratory tests were performed.

The prescription of antimalarials and iron supplements were provided, not as routine or being based on any guidelines or protocol, but at times the midwife's own judgment or upon the pregnant woman's request. Unfortunately for those women who required medicines for other illnesses, they often did not receive them, because they were not available.

After the examination, the women were given their next appointments. These were spaced one month apart until the end of the 36th week of gestation, and were then spaced at one weekly intervals afterwards.

Care that was provided to follow up mothers did not differ by parity, gestation age or previous number of visits. However, it was observed that women who were cleaner and better dressed received better attention, and the communication and information from the clinic staff was better.

\section{DISCUSSION}

The introduction of quality reproductive health services represents an advancement in improving maternal health. However, its introduction alone does not ensure its delivery. The main objective of this study was to examine women's use of maternal services at Chilomoni health centre, their assessment and satisfaction with the quality of maternity care they received. Although the study was limited to a catchment area around one peri- urban health centre, it was sufficient to attain the study objectives and provide reliable information. Variability in the women's responses as to whether or not certain elements of care took place and their varied responses to different indicators within these elements suggest that women pay attention to the details of the quality of care they are offered. The extent of agreement between women's reports and the centre observations by the investigators support this suggestion.
Therefore findings of this study bring out some important points which can be of value in the future planning and management of maternity services, particularly as regards the quality of care factors which facilitate or inhibit women's use of maternity services in Malawi as a whole, and in the Blantyre district in particular.

This study demonstrated that antenatal attendance at Chilomoni health centre was fairly good, even though many mothers did not use the health centre for delivery. In terms of provision of a quality antenatal care and delivery services as means of maternal morbidity and mortality prevention, this relatively low antenatal attendance, the very low rate of deliveries plus the generally expressed dissatisfaction, about the facilities offered at the health centre, is a major concern, and it is indeed a sign of the failure by the authorities in the provision of quality care at this health unit.

Many women indicated that although they were welcomed and treated cordially by the health providers, in many cases they received a very small share of the provider's time and attention. Many women indicated that the woman-provider relationship lacked privacy, as evidenced by the fact that, during the physical examination performed by the midwives, the door was not always properly closed and other health workers would suddenly open it in the midst of the examination resulting in embarrassment of the woman being examined. In addition discussions between the woman and the midwives could be heard clearly by other women. All this contributed greatly to the lack of use of Chilomoni health centre by those women needing the services offered.

Despite the women's dissatisfaction with the facilities, a high proportion of them were satisfied with many of the other elements of the quality of care. This selectivity in satisfaction may be attributed to many factors, including women's expectations of care, as a result of the knowledge gained from health education, on the radio and other sources, previous experiences gained from using other health facilities and their perceptions of the government health system.

The majority of women were satisfied with indicators of provider competence. However, it is possible that the satisfied women were unable to differentiate between the aspects of adequate and inadequate competence. Also the satisfaction responses could have been influenced by the fact that one of the interviewers was a staff member from Chilomoni health centre. On the other hand, despite the technical nature of the issue of provider competence, these responses can be used by the relevant authorities to bridge any service gaps that do exist.

Although only seventeen per cent of the respondents were satisfied with the waiting time, this information tends to contradict what is generally practised. Many of these women are housewives who take advantage of their visits to the health centre to socialise together. The results of observations at the health centre itself showed that many of the women spent a lot of time talking with their friends after finishing their business with the health 
providers. Thus, the long waiting time should not have affected their satisfaction. Similar observations on waiting time were made by other researchers(10) about the socalled "long waiting time", whereby the authors suggest that this term may not be relevant in all cultures and settings.

\section{REFERENCES}

1. Lule, G. Mtitimila E. Intention to deliver and delivery outcome. Malawi Med. J. 1993; 9: 15-17.

2. Phoya, A.M.M., Mslomba, R.G., Chawani, F.S. et al. Service related factors contributing to maternal mortality in hospitals in Malawi. Lilongwe; Ministry of Health and Population. 1992; 27: 13 .

3. Ministry of Health and Population, Malawi. Health policy framework, Lilongwe; Ministry of Health and Population, 1995.
4. Herz, R. Measham, B. and Measham, A. The Safe Motherhood Initiative, Proposals for Action. World Bank Discussion Paper 9. 1987. Washington, DC: World Bank.

5. World Health Organization. Department of Reproductive Health and Research. Action for Safe Motherhood. 1997. WHO Geneva.

6. World Health Organization. Maternal Health and Safe Motherhood Programme Progress Report. 1990. WHO Geneva.

7. Lwanga, S.K. and Lemoshow, S. Tables of the minimum sample size determination in health studies. A Practical manual. WHO, Geneva 1992; 25.

8. Baker, D.J.P. Practical Epidemiology, $3^{\text {rd }}$ edn; Churchill Livingstone, Edinburgh. UK. 1982; 37-38.

9. Bruce, J. Fundamental elements of quality of care: A simple framework. Stud. Fam. Plann. 1990; 21: 61-91.

10. Leslie, J., Gupta, G. Utilization of formal services for maternal nutrition and health care in the Third World. International. Centre for Research on Women, 1989. 